\title{
IMPLEMENTASI SISTEM KEAMANAN AES 256-BIT GCM GUNA MENGAMANKAN DATA PRIBADI
}

\author{
Ega Shela Marsiani $^{1}$, Irawan Setiadi ${ }^{2}$, Alqomari Cahyo ${ }^{3}$ \\ Program Studi Teknik Informatika, Fakultas Teknik dan Ilmu Komputer, \\ Universitas Indraprasta PGRI \\ Jalan Raya Tengah No 80, Kelurahan Gedong, Pasar Rebo, Jakarta Timur \\ egashela@gmail.com ${ }^{1}$, irawan.setiadi91@gmail.com²,$\underline{\text { alqomari.cahyo@gmail.com }}{ }^{3}$
}

\begin{abstract}
Abstrak
Perkembangan teknologi yang semakin cepat dapat dimanfaatkan oleh manusia. Pemanfaatan teknologi yang dilakukan manusia adalah untuk berkomunikasi, mempermudah pekerjaan, dan memperolehinformasi. Tetapi dibalik semuanya itu, teknologi memiliki kelemahan. Kelemahan dari teknologi ialah kurangnya keamanan terhadap data pribadi. Keamanan data merupakan hal yang perlu diperhatikan karena data tersebut bisa dicuri oleh pihak ketiga apabila tidak memiliki sistem keamanan data. Salah satu cara agar data dapat diamankan oleh sistem adalah dengan Kriptografi. Kriptografi adalah penerapan dan studi tentang teknik pengamanan komunikasi maupun data terhadap pihak ketiga/musuh. AES-256 Bit merupakan algoritma kriptografi yang dapat digunakan untuk mengamankan data. AES-256 Bit merupakan blokchipertext simetrik yang dapat mengenkripsi dan dekripsi data/informasi dengan ukuran kunci 256 bit. Dengan menggunakan AES-256 Bit keamanan data tersebut dapat terjaga karena algoritma tersebut melakukan pengamanan dan penyandian yang berlapis-lapis.
\end{abstract}

Kata Kunci : Kriptografi, AES-256 Bit, Enkripsi, Dekripsi

\begin{abstract}
The rapid development of technology can be utilized by humans. Human technology is used to communicate, facilitate work, and obtain information. But behind it all, technology has its drawbacks. The downside of technology is the lack of security over personal data. Data security is a concern because it can be stolen by third parties if it does not have a data security system. One way that data can be secured by the system is by Cryptography. Cryptography is the application and study of communication and data security techniques against third parties / enemies. AES-256 Bit is a cryptographic algorithm that can be used to secure data. AES-256 Bit is a symmetric blokchipertext that can encrypt and decrypt data/information with a key size of 256 bits. By using AES-256 Bit data security can be maintained because the algorithm performs multilayered security and encoding.
\end{abstract}

Keyword : Cryptography, AES-256 Bit, Encryption, Decryption

\section{PENDAHULUAN}

Di zaman sekarang, teknologi terus berkembang dengan pesat. Perkembangan teknologi ini dimanfaatkan oleh setiap manusia untuk mempermudah pekerjaan, berkomunikasi, hingga memperoleh informasi. Kemudahan yang diberikan teknologi, memang sangat bermanfaat untuk setiap manusia. Tetapi dibalik kemudahan yang diberikan, teknologi memiliki kelemahan. Kelemahan dari teknologi ialah kurangnya keamanan ataupun kerahasiaan data pribadi. Sistem keamanan mempunyai peranan penting dalam penggunaan teknologi. Para pengguna akan mempertimbangkan sistem keamanan dalam teknologi tersebut sebelum menggunakannya. Jika keamanan dalam teknologi tidak terjamin, maka akan merugikan para pengguna maupun yang membuat teknologi tersebut. Salah satunya ialah kebocoran data-data pribadi para pengguna. Untuk itu, penulis akan memperkenalkan salah satu sistem keamanan guna mengamankan data-data pribadi yaitu algoritma kriptografi AES-256 Bit GCM.

\section{PENELITIAN RELEVAN}

Menurut penelitian Agustan Latif yang berjudul "IMPLEMENTASI KRIPTOGRAFI MENGGUNAKAN METODE ADVANCED ENCRYPTION STANDAR (AES) UNTUK PENGAMANAN DATA TEKS" adalah sebegai berikut :

1. Sistem kriptografi AES-128 bit dapat berjalan dengan baik mulai dari plainteks dienkripsi dan 
menghasilkan teks yang terenkripsi menggunakan metode AES 128 bit, kemudian ketika teks tersebut dilakukan proses dekripsi menjadi plainteks berhasil dilakukan dan menghasilkan teks sesungguhnya atau teks asli.

2. Berdasarkan hasil pengujian kapasitas enkripsi dan dekripsi diperoleh hasil bahwa kapasitas data teks yang telah dienkripsi lebih besar daripada data teks sebelum di enkripsi. Sedangkan untuk kecepatan komputasi diperoleh hasil bahwa kecepatan komputasi dekripsi lebih cepat di bandingkan dengan waktu komputasi untuk proses enkripsi.

Menurut kami, penelitian tersebut sangat bermanfaat karena dapat mengetahui bagaimana cara mengamankan data teks dengan menerapkan algoritma kriptografi AES-128 Bit. Namun akan lebih baik apabila algoritma yang digunakan adalah algoritma kriptografi AES-256 Bit karena algoritma tersebut memiliki sistem keamanan yang lebih terjamin. Bukan hanya data teks saja yang dapat diamankan tetapi seluruh file yang ada secara khusus file pribadi akan mendapatkan keamanan yang lebih terjamin dibandingkan dengan algoritma kriptografi AES-128 Bit.

\section{METODE PENELITIAN}

Penulisan jurnal ini menggunakan metode penelitian kepustakaan yang mengumpulkan informasi dan data dari berbagai macam sumber. Adapun sumber materi pada jurnal ini berupa jurnal ilmiah, situs internet, serta sumber lain yang memiliki relevansi dengan isi jurnal ini. Tujuan kami menggunakan metode ini yaitu, untuk memberikan solusi agar sistem keamanan pada teknologi semakin efektif dan efisien guna mengamankan data-data pribadi para pengguna.

\section{HASIL DAN PEMBAHASAN}

\begin{tabular}{|c|c|c|c|}
\hline \multirow[t]{2}{*}{ Key $\$ i z t$} & \multirow{2}{*}{$\begin{array}{l}\text { Possible } \\
\text { combinations }\end{array}$} & Keysize & Time to Crack \\
\hline & & 96.611 & 399 seconds \\
\hline 1.61 & 2 & 128.61 & $1.02 \times 10$ yous \\
\hline $2 \cdot 6 \mathrm{bt}$ & 4 & 192.611 & $1.872 \times 10^{1}$ years \\
\hline $4 b i$ & 16 & $256-64$ & $3.31 \times 10^{\circ}$ years \\
\hline 8.64 & 256 & & \\
\hline 16011 & 65536 & & \\
\hline 32.611 & $4.2 \times 10$ & & \\
\hline 56-Dil (OES) & $7.2 \times 10^{6}$ & & \\
\hline $64 \mathrm{bth}$ & $18 \times 10^{11}$ & & \\
\hline 12B.6A (AES) & $34 \times 10^{21}$ & & \\
\hline 192-01I (AES) & $6.2 \times 10^{2}$ & & \\
\hline 256-0H (AES) & $1.1 \times 10^{11}$ & & \\
\hline
\end{tabular}

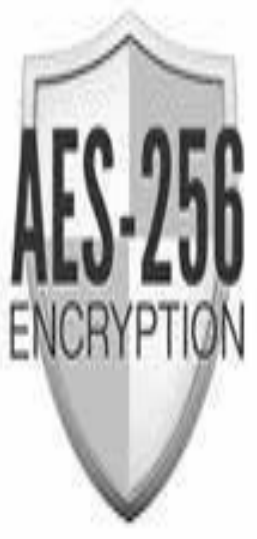

Gambar 1. Possible combinations and Time to Crack AES-256 Bit

Proses enkripsi algoritma AES 256 (gambar 2) terdiri dari 4 (empat) jenis transformasi yang akan dijalankan, yaitu SubBytes, ShiftRows, MixColumns dan AddRoundKey awal proses enkripsi, input yang telah disamakan atau diduplikasi ke dalam state akan mengalami transformasi SubBytes, ShiftRows, Mixcolumns dan AddRoundKey secara berulang sesuai banyaknya $\mathrm{Nr}=10$, jumlah kunci $\mathrm{Nk}=8$ dan ukuran blok $\mathrm{Nb}=4$. 


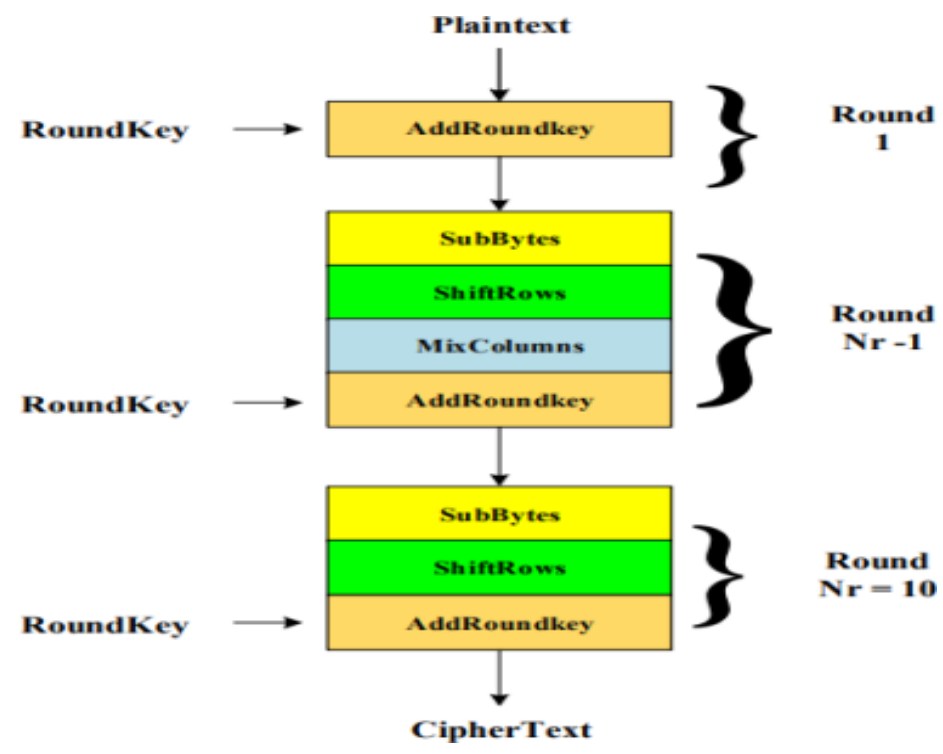

Gambar 2. Proses Enkripsi AES-256 Bit

AddRoundKey

Pada proses transformasi enkripsi dan dekripsi AES 256-bit, sebuah round key ditambahkan pada state dengan operasi XOR. Setiap round key terdiri dari $\mathrm{Nb}$ word di mana tiap word tersebut akan dijumlahkan dengan word atau kolom yang bersetaraan wi [9] dari state sehingga :

$$
\text { [s'o,c , s'1,c , s'2,c , s'3,c ]* }
$$

$[\mathrm{so}, \mathrm{c}, \mathrm{s} 1, \mathrm{c}, \mathrm{s} 2, \mathrm{c}, \mathrm{s} 3, \mathrm{c}] \oplus[\mathrm{wround} * \mathrm{Nb}+\mathrm{c}]$

Dengan $\mathrm{i}=$ round $* \mathrm{Nb}+\mathrm{c}$.

SubBytes

SubBytes merupakan transformasi byte dimana setiap elemen pada state akan dipetakan dengan menggunakan sebuah tabel subtitusi (S-Box). Tabel subtitusi S-Box akan dipaparkan dalam tabel 1. Untuk setiap byte pada array state, misalkan $S[r, c]=x y$, yang dalam hal ini $x y$ adalah digit heksadesimal dari nilai S[r,c], maka nilai subtitusinya, dinyatakan dengan S[r,c], adalah elemen di dalam tabel subtitusi yang merupakan pengaruh pemetaan byte pada setiap byte dan state.

Tabel 1. S-Box

\begin{tabular}{|c|c|c|c|c|c|c|c|c|c|c|c|c|c|c|c|c|}
\hline & $x 0$ & $\mathbf{x} 1$ & $x 2$ & $x^{3} 3$ & $\times 4$ & $x 5$ & $x 6$ & $x 7$ & $x 8$ & $x^{9}$ & xa & $x b$ & $x c$ & $x d$ & xe & $x \in$ \\
\hline $0 x$ & 63 & $7 \mathrm{c}$ & 77 & $7 b$ & $f 2$ & $6 b$ & $6 f$ & $c 5$ & 30 & 01 & 67 & $2 b$ & $\mathrm{fe}$ & d7 & $a b$ & 76 \\
\hline $1 x$ & $\mathrm{ca}$ & 82 & $c 9$ & $7 d$ & fa & 59 & 47 & 50 & ad & d4 & $a 2$ & af & $9 e$ & $a 4$ & 72 & $c 0$ \\
\hline $2 \mathrm{x}$ & b7 & fd & 93 & 26 & 36 & $3 f$ & E7 & $\mathrm{ce}$ & 34 & as & e5 & $\mathrm{E} 1$ & 71 & d8 & 31 & 15 \\
\hline $3 x$ & 04 & c7 & 23 & $c 3$ & 18 & 96 & 05 & $9 a$ & 07 & 12 & 80 & $e^{2}$ & eb & 27 & b2 & 75 \\
\hline $4 x$ & 09 & 83 & $2 c$ & Ia & $1 \mathrm{~b}$ & $6 \mathrm{e}$ & $5 a$ & $\mathrm{ac}$ & 52 & $3 b$ & $d 6$ & b3 & 29 & $e 3$ & $2 f$ & 84 \\
\hline $5 x$ & 53 & d1 & 00 & ed & 20 & fe & b1 & $5 b$ & $6 a$ & $c b$ & be & 39 & $4 a$ & $4 c$ & 58 & cf \\
\hline $6 x$ & do & ef & aa & $\mathrm{fb}$ & 43 & $4 d$ & 33 & 85 & 45 & $f 9$ & 02 & $7 f$ & 50 & $3 c$ & 91 & 18 \\
\hline $7 x$ & 51 & a 3 & 40 & $8 f$ & 92 & $9 d$ & 38 & 55 & be & b6 & da & 21 & 10 & fE & f3 & $d 2$ \\
\hline $8 x$ & ed & Oe & 13 & ec & $5 f$ & 97 & 44 & 17 & $c^{4}$ & a7 & $7 e$ & $3 d$ & 64 & $5 d$ & 19 & 73 \\
\hline $9 x$ & 60 & 81 & If & $d e$ & 22 & $2 a$ & 90 & 88 & 46 & ee & b8 & 14 & de & $5 e$ & $O b$ & db \\
\hline$a x$ & $e 0$ & 32 & $3 a$ & $\mathrm{Oa}$ & 49 & 06 & 24 & 50 & $c 2$ & d3 & $a c$ & 62 & 91 & 95 & e4 & 79 \\
\hline$b x$ & e? & $c^{8}$ & 37 & $6 d$ & $8 d$ & $d 5$ & 4e & a9 & $6 c$ & 56 & 14 & ea & 65 & $7 a$ & ae & 08 \\
\hline $\mathrm{cx}$ & ba & 78 & 25 & $2 \mathrm{e}$ & $1 \mathrm{c}$ & a6 & $b 4$ & $c 6$ & e8 & $d d$ & 74 & 1f & $4 b$ & bd & $8 b$ & $8 \mathrm{a}$ \\
\hline$d x$ & 70 & $3 e$ & b5 & 66 & 48 & 03 & f6 & $\mathrm{Oe}$ & 61 & 35 & 57 & b9 & 86 & c1 & $1 d$ & $9 e$ \\
\hline ex & e1 & $f 8$ & 98 & 11 & 69 & $d 9$ & $8 \mathrm{e}$ & 94 & $9 b$ & 1e & 87 & e9 & ce & 55 & 28 & df \\
\hline$f x$ & $8 \mathrm{c}$ & al & 89 & $0 d$ & $b f$ & e6 & 42 & 68 & 41 & 99 & $2 d$ & $0 f$ & bo & 54 & $\mathrm{bb}$ & 16 \\
\hline
\end{tabular}




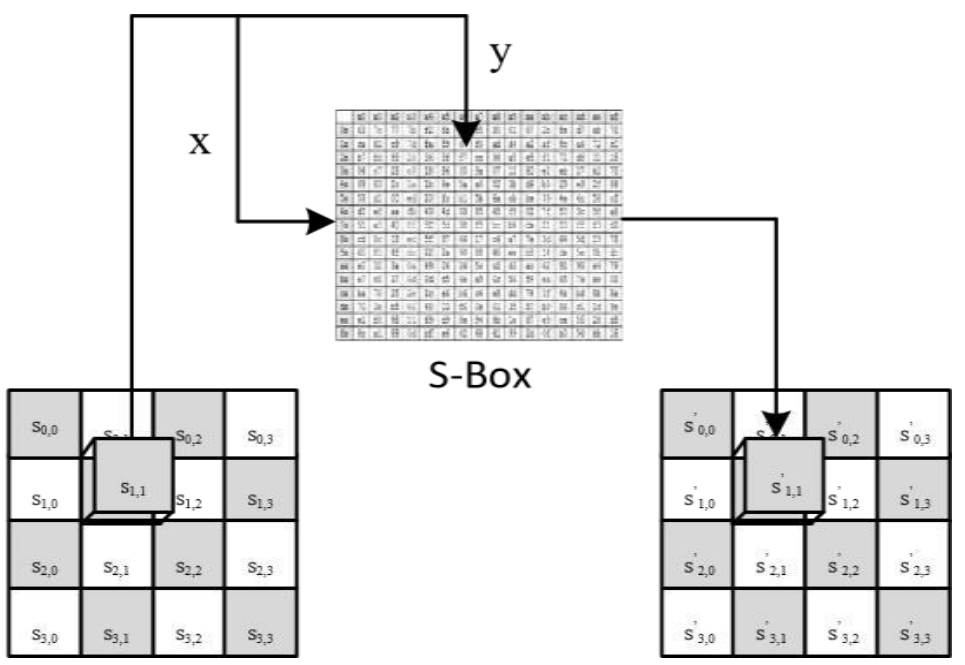

Gambar 3. Pengaruh Pemetaan pada setiap byte dalam state

ShiftRows

Shift Rows adalah sebuah proses yang melakukan pergeseran dalam elemen blok/tabel yang harus dilakukan per baris, baris pertama tidak harus dilakukan pergeseran 2 byte lalu setelah itu baris yang keempat dilakukan pergeseran 3 bytes, berikut pada gambar 4 .

\begin{tabular}{|l|l|l|l|}
\hline $\mathrm{s}_{0,0}$ & $\mathrm{~s}_{0,1}$ & $\mathrm{~s}_{0,2}$ & $\mathrm{~s}_{0,3}$ \\
\hline $\mathrm{s}_{1,0}$ & $\mathrm{~s}_{1,1}$ & $\mathrm{~s}_{1,2}$ & $\mathrm{~s}_{1,3}$ \\
\hline $\mathrm{s}_{2,0}$ & $\mathrm{~s}_{2,1}$ & $\mathrm{~s}_{2,2}$ & $\mathrm{~s}_{2,3}$ \\
\hline & & & \\
$\mathrm{s}_{3,0}$ & $\mathrm{~s}_{3,1}$ & $\mathrm{~s}_{3,2}$ & $\mathrm{~s}_{3,3}$ \\
\hline
\end{tabular}
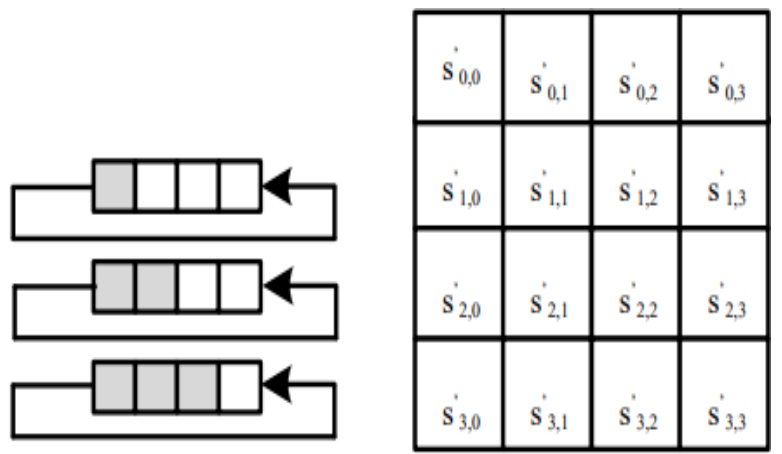

Gambar 4. Proses ShiftRows

MixColumns

MixColumn adalah proses perkalian tiap elemen dari blokcipher dengan matriks (gambar 5 dan persamaan 2).

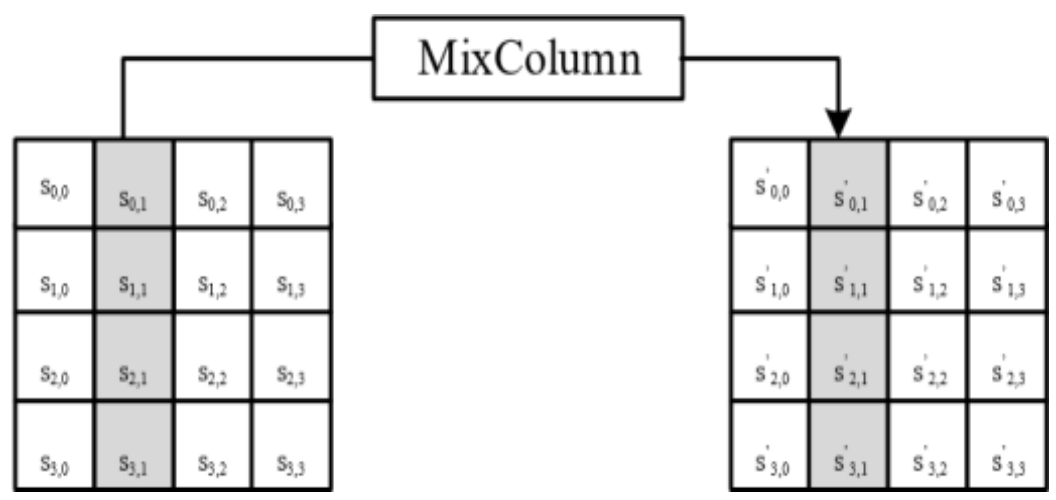

Gambar 5. MixColumn 


$$
\left(\begin{array}{l}
s^{\prime} 0,1 \\
s^{\prime} 1,1 \\
s^{\prime} 2,1 \\
s^{\prime} 3,1
\end{array}\right)=\left(\begin{array}{llll}
2 & 3 & 1 & 1 \\
1 & 2 & 3 & 1 \\
1 & 1 & 2 & 3 \\
3 & 1 & 1 & 2
\end{array}\right)\left(\begin{array}{l}
s 0,1 \\
s 1,1 \\
s 2,1 \\
s 3,1
\end{array}\right)
$$

Proses Dekripsi AES-256 bit, tahapan transformasi byte digunakan proses invers cipher ke plaintext adalah InvShiftRows, InvSubBytes, InvMixColumns, dan AddRoundKey. Algoritma dekripsi dapat dilihat pada skema (gambar 6)

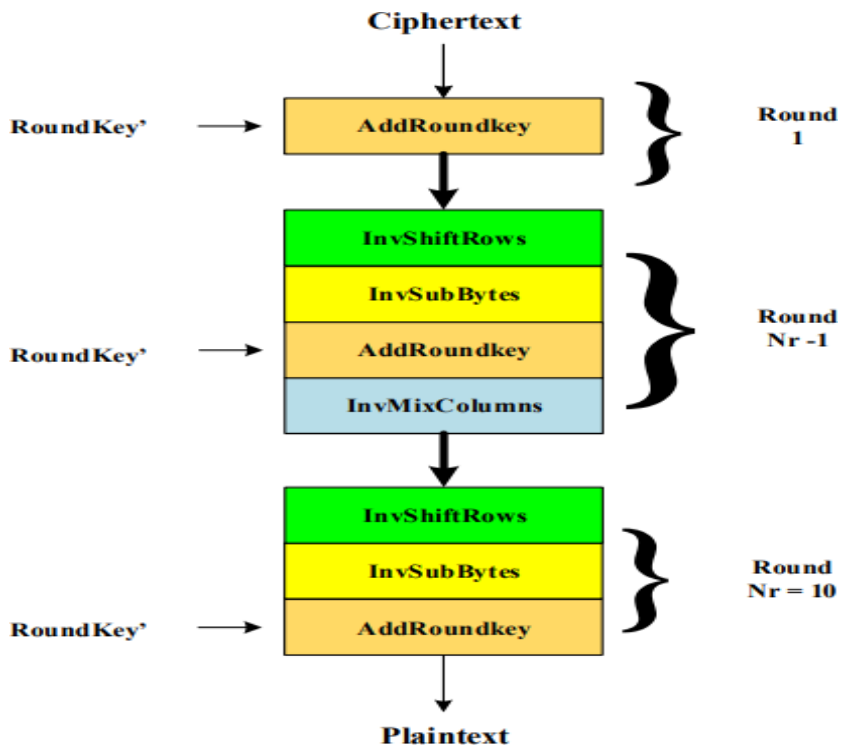

Gambar 6. Proses Dekripsi AES-256 Bit

Semua pengguna komputer atau pun smartphone memiliki banyak data pribadi dan juga memiliki data penting yang merupakan milik perusahaan. Semua pengguna tidak ingin data yang dimiliki hilang. Apabila data tersebut hilang hal itu akan merepotkan para penggunanya karena harus mencari atau membuat data yang baru yang menyerupai dengan data sebelumnya. Penjelasan diatas merupakan cara kerja sistem keamanan AES-256 Bit. Sistem keamanan tersebut dapat dipakai guna mengamankan semua data-data yang dimiliki pengguna.

Windows memiliki fitur yang bernama BitLocker. Fitur ini menggunakan algoritma kriptografi AES- 256 Bit yang mana fitur ini berfungsi untuk mengenkripsi partisi sehingga data data tersebut dapat diamankan dan hanya bisa diakses apabila pengguna memiliki atau mengetahui password untuk mengakses partisi tersebut. Fitur ini hanya terdapat pada Windows Vista, 7, 8, dan 10 edisi Professional, Enterprise, dan Education. Berikut ini adalah tampilan penggunaan fitur BitLocker dengan metode AES-256 bit:

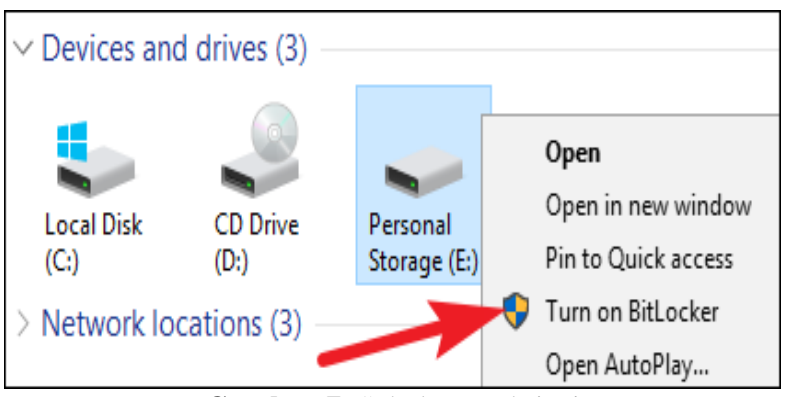

Gambar 7. Sebelum Enkripsi 


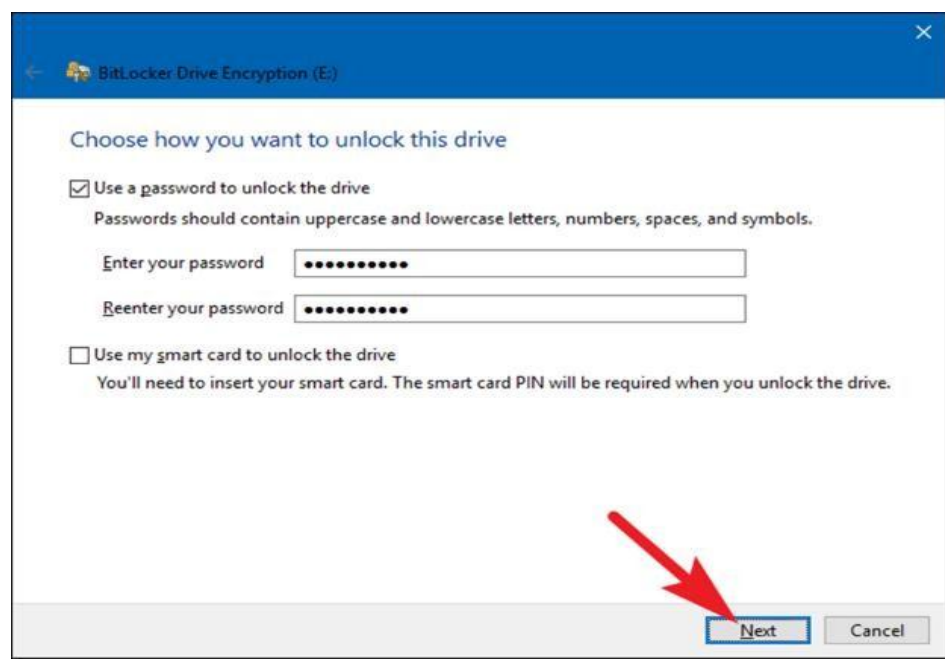

Gambar 8. Pembuatan Enkripsi

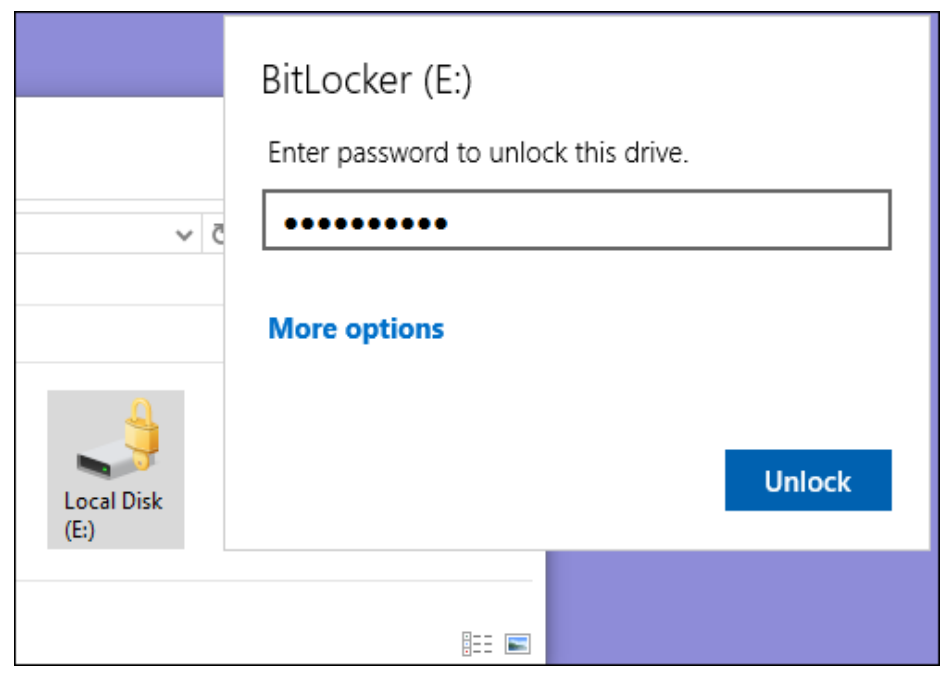

Gambar 9. Sesudah Enkripsi

Gambar 7-9 merupakan tampilan pembuatan enkripsi pada partisi yang terdapat di windows. Apabila seseorang ingin mengakses partisi yang sudah di enkripsi, orang tersebut harus mengetahui password untuk mengakses partisi tersebut.

\section{SIMPULAN}

Berdasarkan hasil dan pembahasan diatas, enkripsi data atau file merupakan hal penting karena data yang kita enkripsi akan aman. Salah satunya adalah dengan menggunakan metode AES-256 Bit. Dengan menggunakan AES-256 Bit data tersebut akan kebal menghadapi serangan konvensional yang menggunakan statistik untuk memecahkan sandi. Salah satu program yang sudah menggunakan metode AES 256-bit adalah windows. Dengan mengoptimalkan sistem keamanan yang ada di windows data yang dimiliki pengguna akan aman terhadap ancaman.

\section{DAFTAR PUSTAKA}

[1] N. Anwar, M. Munawwar, M. Abduh, and N. B. Santosa, "Komparatif Performance Model Keamanan Menggunakan Metode Algoritma AES 256 bit dan RSA,” J. RESTI (Rekayasa Sist. dan Teknol. Informasi), 2018.

[2] G. Bhaudhayana and I. Widiartha, "Implementasi Algoritma Kriptografi Aes 256 Dan Metode Steganografi Lsb Pada Gambar Bitmap,” J. Ilmu Komput., 2015.

[3] A. Marisman and A. Hidayati, "PEMBANGUNAN APLIKASI PEMBANDING KRIPTOGRAFI DENGAN CAESAR CIPHER DAN ADVANCE ENCRYPTION STANDARD (AES) UNTUK FILE TEKS,” J. Penelit. Komun. dan Opini Publik, 2015. 
[4] F. Nuraeni and Y. H. Agustin, "The IMPLEMENTASI CAESAR CIPHER \& ADVANCED ENCRYPTION STANDAR (AES) PADA PENGAMANAN DATA PAJAK BUMI BANGUNAN," J. Ilm. Matrik, 2020.

[5] F. N. Pabokory, I. F. Astuti, and A. H. Kridalaksana, "Implementasi Kriptografi Pengamanan Data Pada Pesan Teks, Isi File Dokumen, Dan File Dokumen Menggunakan Algoritma Advanced Encryption Standard,” Inform. Mulawarman J. Ilm. Ilmu Komput., 2016.

[6] A. R. Tulloh, Y. Permanasari, and E. Harahap, "Kriptografi Advanced Encryption Standard ( AES ) Untuk Penyandian File Dokumen," J. Mat. UNISBA, 2016.

[7] A. Prameshwari and N. P. Sastra, "Implementasi Algoritma Advanced Encryption Standard (AES) 128 Untuk Enkripsi dan Dekripsi File Dokumen,” Eksplora Inform., 2018.

[8] O. K. Sulaiman, K. Nasution, and S. Y. Prayogi, "Enkripsi Surat Elektronik Menggunakan Metode XXTEA,” Comput. Eng. Sci. Syst. J., 2019. 